\title{
PROCESSO DE BOLONHA E ENSINO SUPERIOR NUM MUNDO GLOBALIZADO
}

\author{
José Carlos Morgado*
}

\begin{abstract}
RESUMO: Partindo de uma série de transformações económicas, sociais e culturais provocadas pela recente avalanche globalizadora, procuramos ao longo deste texto analisar algumas das mudanças que devem operar-se no terreno da educação, de modo a que as instituições de ensino e os professores que nelas laboram possam desenvolver processos de ensino-aprendizagem norteados por critérios de democracia, inclusão e justiça, contribuindo assim para (re)construir uma escola capaz de responder às expectativas que sobre ela impendem. Questionamos ainda a importância do currículo nesse empreendimento, uma vez que se configura como um dos principais instrumentos de produção de identidades pessoais, culturais e sociais.
\end{abstract}

Palavras-chave: Globalização. Processo de Bolonha. Ensino superior. Currículo.

\section{Bologna Process and higher education in a globalized world}

ABSTRACT: Deriving from a series of economic, social and cultural transformations resulting from the recent globalization surge, we analyze some of the changes that ought to take place in the field of education so that teaching institutions and teachers alike can develop teaching-learning processes guided by criteria of democracy, inclusion and justice and so that schooling may realize the expectations placed on it. Since it is one of the main instruments in the production of personal, cultural and

Doutor em Educação e professor e investigador na Universidade do Minho (Braga, Portugal).E-mail: jmorgado@iep.uminho.pt 
social identities, we also question the importance of curriculum in that undertaking.

Key words: Globalization. Bologna Process. Higher education. Curriculum.

\section{Introdução}

$F$

alar das transformaçóes que ocorrem no ensino superior, no quadro da actual globalização, não é tarefa fácil, dadas as múltiplas perspectivas de análise que podemos adoptar, o conjunto de variáveis que condicionam e complexificam todo esse processo e, ainda, por tudo o que se tem escrito e comentado acerca desta problemática. Contudo, tal dificuldade não deve eximir-nos de reflectir em torno de um tema tão candente, sobretudo se o ensejo for o de contribuir, ainda que de forma modesta, para ajudar a compreender os efeitos das dinâmicas da globalização no campo da educação e a desocultar algumas tendências que, sob a égide da mudança e melhoria do sistema educativo, visam interferir no próprio modelo de gestão social e na conformação de alguns traços fundamentais que caracterizam as sociedades contemporâneas.

Partindo de algumas transformações que a globalização tem provocado aos mais diversos níveis, procuramos neste texto reflectir sobre um conjunto de mudanças que devem ocorrer no âmbito da educação, de modo a que as instituições de ensino e os professores que nelas trabalham desenvolvam processos de ensino-aprendizagem norteados por critérios de democracia, inclusão e justiça, contribuindo assim para (re)construir uma escola capaz de responder às expectativas que sobre ela recaem. Procuramos ainda reflectir sobre a importância do currículo nesse empreendimento, uma vez que se configura como um dos principais instrumentos de produção de identidades pessoais, culturais e sociais.

\section{Globalização e educação}

A globalização é um fenómeno que se intensificou drasticamente nas últimas décadas, tornando-se impossível ignorá-la quer quando analisamos o tempo presente, tentando compreender os efeitos que a catadupa de transformaçóes políticas, económicas, sociais e culturais 
provocou (e continua a provocar) no nosso dia-a-dia, quer quando especulamos sobre o futuro, procurando vislumbrar os sinais dos tempos vindouros e idealizar soluções para os desafios e problemas que todo esse processo gerou.

Aplaudida por uns, que a idealizam como a nova utopia dos cosmopolitas e vêem satisfeitas grande parte das suas aspirações, odiada por outros, que sentem na pele os efeitos nefastos de tal processo, o que se verifica é que a globalização não tem tido o mesmo alcance, nem tem avançado ao mesmo ritmo, tanto ao nível das diversas regióes do mundo quanto das distintas vertentes que integra. Boaventura Santos (2002, p. 33) identifica-a como "um vasto e imenso campo de conflitos entre grupos sociais, Estados e interesses hegemónicos, por um lado, e grupos sociais, Estados e interesses subalternos, por outro", associados à emergência de uma nova divisão internacional do trabalho, num cenário económico onde as empresas multinacionais passaram a assumir um lugar central, com implicações para as políticas nacionais dos vários países, que se vêem compelidos a responder a uma série de exigências da economia mundial e a proceder a reestruturações internas. ${ }^{1}$

$\mathrm{Na}$ verdade, ao invés de conseguir a desejável integração harmoniosa das economias e uma maior unidade política, cultural e social no mundo, a globalização tem, em muitos casos, contribuído para tentar "impor" determinados padrôes e estilos de vida, para estimular o consumo e a competição desenfreada entre empresas e trabalhadores e para acentuar, de forma dramática, a percepção das desigualdades que continuam a grassar no planeta.

Adia-se, assim, o cumprimento das promessas de igualdade de oportunidades, de bem-estar e prosperidade inscritas no projecto da modernidade e que deviam nortear todo o processo de globalização, conduzindo ao desenvolvimento sustentado dos países e dos povos e a uma repartição mais equitativa da riqueza. Não subestimando algumas melhorias conseguidas nos últimos anos, os números que vão sendo divulgados pelos sucessivos Relatórios do Desenvolvimento Humano, das Naçôes Unidas, são ainda demasiado escandalosos para deixarem de nos envergonhar:

No meio de uma economia global cada vez mais próspera, 10,7 milhões de crianças por ano não vivem para ver o seu quinto aniversário e mais 
de mil milhões de pessoas sobrevivem numa pobreza abjecta, com menos de 1 dólar por dia. (PNUD, 2005, p. 17)

Não deixa de ser paradoxal o facto de, num momento em que o mundo se orgulha dos extraordinários progressos da ciência, da tecnologia, da indústria e da acumulação de riqueza, continuar a verificar-se a exclusão de largas parcelas da humanidade de tais benefícios e a proliferarem fenómenos de pobreza extrema e de desigualdade atroz. Uma situação preocupante que tanto os países ricos como os países pobres afirmam querer resolver, assumindo que a redução "do abismo de riqueza e de oportunidade que divide a comunidade humana" não se pode equacionar como "um jogo de soma zero", onde alguns tenham de perder para que outros ganhem (idem, ibid.). É nessa ordem de ideias que António Lopes (2006, p. 41) defende que o actual modelo de desenvolvimento deve assentar mais na repartição como forma de promover a dignificação humana, sendo ilegítimo "continuar a fazer esperar os mais pobres até que sejamos todos mais ricos”.

Todavia, apesar das louváveis intenções de muitos responsáveis, sabemos que tais propósitos têm servido mais de mera retórica moralista, sendo sucessivamente adiadas quer as decisões de fundo, quer as acções no terreno que conduziriam à sua concretização.

Na opinião de Santos (2002, p. 43-44), tal incapacidade tem a ver com a perda de centralidade do Estado-nação como "unidade privilegiada de iniciativa económica, social e política”, situação a que não é alheia a tendência cada vez maior de estabelecer "acordos políticos interestatais" (como nos casos da União Europeia, da NAFTA e do MERCOSUL), a emergência de uma "nova divisão internacional do trabalho", o aumento das transacçōes económicas transnacionais e a constante pressão internacional no sentido da unificação e da normalização. Em idêntica linha de pensamento Bob Jessop (2005, p. 17-18) considera que:

(...) a globalização enfraquece a capacidade dos Estados nacionais em conduzir a expansăo do capital num cenário de segurança nacional (visível na "segurança nacional do Estado"), segurança social (visível na segurança social do Estado democrático), ou outros projectos nacionais com uma posição espacio-temporal adequada. E, contrariamente, aumenta a pressão nos Estados nacionais para ajustar aos horizontes do tempo e temporalidades do capital móvel capaz de operar além das suas próprias fronteiras. 
Ao progressivo enfraquecimento do Estado nacional, afirma Santos (op. cit, p. 49), contrapõe-se a concomitante ascensão do "primado do direito e do sistema judicial”, operacionalizado por um conjunto de instituiçóes independentes e universais que, em resposta à perda de poder de comando do Estado, passam a assegurar os princípios da ordem, da previsibilidade e da confiança. Uma mudança que não pode dissociar-se da passagem de um período fundado numa relação espaçotempo nacional para outro, em que prevalece o binómio espaços-tempos global e local e que torna visível a falência do contrato social nacional (Santos, 1998) que imperou ao longo da modernidade e serviu de matriz ao desenvolvimento e consolidação do Estado-nação.

Todos estes factos têm contribuído para que a anunciada prosperidade, resultante da internacionalização, da progressiva substituição do Estado pelo mercado no domínio da regulação social, da livre circulação de capitais e da criação de uma economia de mercado de âmbito global, que em conjunto fariam aproximar os mais desfavorecidos dos níveis mínimos aceitáveis de desenvolvimento, continue muito aquém do que seria desejável, servindo mais aos interesses de determinados circuitos financeiros e das grandes multinacionais do que, propriamente, a criação sustentada de riqueza, a diluição das desigualdades e a diminuição da pobreza nas regiões mais carenciadas.

Importa, ainda, referir que as transformaçóes a que vimos aludindo e que conseguiram imprimir alterações significativas nos modos de produção e de organização do trabalho, concorreram para conferir um novo protagonismo ao papel desempenhado pelo pensamento e pela informação nesses processos, com evidentes reflexos em termos de produção e consumo de bens e serviços, nas relações entre as pessoas e na emergência de novas formas de organização económica, política e social (Tedesco, 2000). A este propósito, Riccardo Petrella (2002) lembra que a globalização conseguiu gerar uma obsessão excessiva pela eficácia produtiva e pela rentabilidade financeira, contribuindo para que os valores e os critérios próprios da economia de mercado se impusessem como elementos definidores daquilo que é bom, útil e necessário, e para enfraquecer certos princípios fundadores das modernas sociedades ocidentais, tais como a cidadania, a solidariedade e o bem comum. Uma situação que precisa de ser revista e que, na óptica de Santos (1998, p. 46), passa pela implementação de um novo contrato social, 
mais amplo e inclusivo, que englobe "o homem e os grupos sociais, mas também a natureza”, que veicule uma participação mais activa dos cidadãos e estimule a "redescoberta democrática do trabalho", um contrato que contribua para a assunção de um modelo de democracia redistributiva em detrimento do modelo de democracia representativa que tem imperado nos últimos anos.

Também ao nível cultural a globalização tem interferido de forma significativa na vida de todos e de cada um. O extraordinário desenvolvimento das tecnologias da informação e comunicação, ${ }^{2}$ que contribuiu para aproximar os indivíduos entre si e para aprofundar os seus processos de relação (Gouveia, 2003), acabou por tornar o mundo mais pequeno, conduzindo-nos a pontos do globo e envolvendo-nos em situações até há bem pouco tempo impensáveis. Não deixando de reconhecer novamente a dualidade de posiçóes entre os que acreditam que a globalização não é nenhuma fatalidade, tendo contribuído para enriquecer o mundo nos planos científico e cultural, e os que a consideram como um processo de ocidentalização compulsiva do mundo, responsável pela tentativa de homogeneização das práticas culturais, o aumento do consumismo, a fragmentação de identidades, a perda de valores e o eclodir de novas formas de dominação (idem, ibid.), a verdade é que, independentemente da posição que se possa assumir, a globalização cultural constitui hoje um dos desafios mais gigantescos do século.

Na opinião de Dominique Wolton (2004), a informação, que durante tanto tempo foi considerada um factor fundamental de emancipação e progresso, pode, na conjuntura actual, transformar-se num claro agente de conflituosidade, confirmando assim a inexistência de uma relação directa entre o aumento de informação e a compreensão do mundo. Partindo do pressuposto de que a informação, por si só, não é suficiente para gerar comunicação, considera que o facto da intensificação da globalização da informação ter procurado responder, essencialmente, a imperativos ocidentais de disseminação e consolidação de um determinado modelo político e cultural é uma das principais causas das rupturas e dos conflitos que se têm instalado entre diversas regiões do mundo. Daí a importância do que designa por "outra globalização", para se referir ao processo de globalização cultural que, a par das mudanças políticas e económicas, tem de ser rapidamente equacionado para evitar que se subvertam as relaçóes entre identidade, 
cultura e comunicação. Consegui-lo, afirma Santos (2002, p. 54), só será possível se se evitar que os Estados, os grupos e as classes hierarquicamente mais bem posicionados, e que, por isso, definem as culturas parciais como culturas globais, controlem "a agenda de dominação política sob o disfarce da globalização cultural”.

É que, se, por um lado, a rápida e profunda evolução tecnológica conseguiu diminuir as distâncias físicas entre todos os cidadãos do planeta, a verdade é que, por outro, tal fenómeno tornou visíveis as suas distâncias culturais, fragilizou as suas identidades e esteve na base da emergência do que Wolton (2004, p. 10) denomina como triângulo identidade-cultura-comunicação, para identificar três elementos-chave na configuração do panorama social e na definição das políticas futuras ao nível do mundo. Uma tríade importante se tivermos em conta que a globalização, ao mesmo tempo que fazia aumentar a interdependência dos países e dos povos e a sua mobilidade, evidenciava tanto a necessidade de reforçarem as suas identidades, quanto as dificuldades de uma efectiva coabitação cultural. Contudo, o mais preocupante é a incerteza que perpassa em torno dessa possibilidade de coabitação, já que tanto pode instituir-se no âmbito de um projecto político democrático, o que facilitará a comunicação e a convivência entre distintas culturas, como não chegar a edificar-se, por causa de certos dogmas e irredentismos culturais, podendo nesse caso ser fonte de conflitos políticos e culturais. Trata-se de uma preocupação legítima, se tivermos em conta que ao mesmo tempo que se intensificaram os contactos e aprofundaram as interdependências transfronteiriças, criando condições para "o exercício da tolerância, do ecumenismo, da solidariedade e do cosmopolismo", se geraram "novas formas e manifestações de intolerância, chauvinismo, de racismo, de xenofobia e, em última instância, de imperialismo" (Santos, 2002, p. 55).

No que diz respeito à educação, também a este nível se sentiram os efeitos desta onda globalizadora, em particular no campo das políticas educativas e curriculares que, em resultado da perda de protagonismo dos Estados nacionais em matéria de decisão educativa e da afirmação de novas formas de regulação transnacional, passaram a definir-se numa lógica modelada, entre outras, por duas dinâmicas distintas - por um lado, os movimentos globais e os projectos supranacionais e, por outro, os contextos nacionais concretos, com características e configurações históricas, 
sociais e culturais muito próprias. ${ }^{3}$ Resta saber até que ponto a existência de referenciais educativos comuns, definidos no âmbito da globalização supranacional e das relações de interdependência que se estabelecem entre os diferentes países, não contribuirá para fazer prevalecer imperativos de teor mais globalizante à custa da debilidade das territorialidades nacionais, regionais e locais, avivando ainda mais a crise que se vem instalando nos sistemas de ensino nacionais.

É hoje lugar comum que as intensas mutações políticas, económicas e sociais a que vimos assistindo contribuíram para tornar visíveis algumas incapacidades e debilidades dos sistemas de ensino, agravadas pela emergência da denominada sociedade da informação e do conhecimento, um tipo de sociedade em que o poder deixou de se traduzir apenas em capital financeiro para passar a depender, em muito, da produção e utilização oportuna do conhecimento e das novas tecnologias da informação e comunicação. Nas palavras de Simão et al. (2003, p. 25), tratase de uma nova realidade social e económica, onde "o poder deixou de se concentrar nas mãos do Estado ou de grupos sociais, económicos ou financeiros para se diluir nas mãos de muitos outros, capazes de dominar a informação, assumida como recurso estratégico vital para o bom funcionamento dos governos, das empresas e das instituições".

Em todo este cenário de mudança, onde a posse de determinados saberes e competências se revela imprescindível quer em termos de inserção social e de exercício da cidadania, quer para garantir e preservar a empregabilidade (Azevedo, 2002), quer ainda como forma de coesão social e desenvolvimento equilibrado e sustentado, a educação assume responsabilidades acrescidas. Uma ideia corroborada por Stoer (2001) que, em face do lugar preponderante que a escola ocupa no sistema mundial, reitera a importância da educação quer como energia emancipatória, quer como elemento nuclear na reconversão dos processos de socialização locais, nutrientes indispensáveis para ajudar a diluir excessos reguladores, dinâmicas reprodutoras e lógicas de exclusão típicas da modernidade e para consignar um sentido mais aberto, mais reflexivo e mais emancipador ao fenómeno educativo.

É nesta ordem de ideias que Teodoro (2001, p. 157), partindo do pressuposto de que a escola possui características de lugar estrutural, ${ }^{4}$ considera que "constitui um espaço público de experimentação institucional", propício para se dotarem as actuais e futuras gerações de "novos modos de pensar a construção de um mundo mais justo". Um ensejo 
que, por si só, torna imprescindível a adopção de uma agenda educativa preocupada com a concretização de processos de ensino e aprendizagem pautados por princípios de participação, cidadania, justiça e equidade, isto é, uma agenda educativa preocupada com a construção de uma educação democrática.

Contudo, como referimos atrás, a realidade tem demonstrado que, embora as instituições educativas não tenham estado alheadas dos profundos processos de transformação que perpassam a sociedade actual, por motivos de vária ordem, não têm conseguido lidar com eles da melhor forma, nem dar resposta à maior parte dos reptos que lhe têm sido lançados. ${ }^{5}$ Daí a crise profunda que se instalou no seio da educação.

Não deixando de reconhecer, com Tedesco (2000), que educação e crise são dois termos que têm andado associados com demasiada frequência, justificando até alguma da inacção e do cepticismo com que muitos dos protagonistas do fenómeno educativo reagiam aos projectos de reforma com que se tentava alterar a situação e às críticas de que eram alvo, a verdade é que a actual crise educativa deixou de circunscrever apenas à insatisfação resultante da forma deficiente como a educação cumpre os objectivos que lhe estão confiados, radicando mais na ausência de uma definição clara das finalidades que deve perseguir, bem como dos caminhos que deve percorrer e dos sentidos que devem orientar a sua acção. Uma crise que, no fundo, padece dos sintomas de instabilidade e de incerteza que afectam a própria sociedade e que não é imune aos dilemas e tensões que resultam da alteração dos modos de relacionamento que aí imperam. Uma crise que não é alheia à mudança das relações entre o Estado e a sociedade, com inegáveis reflexos na organização e no funcionamento das instituições educativas, em particular do ensino superior.

Impõe-se, neste momento, perguntar: Que mudanças podem as instituições de ensino superior operar para sair da crise em que actualmente se vêem envolvidas? Que contributos podem propiciar para diluir os efeitos mais nefastos desta força globalizadora que tem assolado a sociedade contemporânea?

\section{Globalização e universidade}

Durante muito tempo, a universidade foi considerada o principal esteio da produção de conhecimento e a entidade responsável pela formação de uma determinada elite, cabendo-lhe ainda a responsabilidade 
de contribuir para a formação da cidadania, a transmissão de valores, a socialização dos estudantes e a formação dos quadros superiores do Estado (Amaral \& Magalhães, 2000).

Herdeira do modelo humboldtiano - em que se consignava aos professores universitários liberdade de ensinar e de investigar sem estarem sujeitos a qualquer programa predefinido -, a universidade era vista como um espaço de "discussão livre e independente das questōes críticas da sociedade", sendo ao mesmo tempo encarada como parceiro do Estado a quem incumbia cooperar na construção da identidade política da nação e na "preservação e desenvolvimento da cultura nacional" (idem, ibid., p. 8). Daí o fato de ser associada à emergência e consolidação do Estado-nação, sendo considerada por muitos como o seu braço ideológico. Por seu turno, ao Estado competia criar condições para a subsistência e bom funcionamento da universidade, bem como a regulação do sistema de ensino, arrogando-se o direito de, ao bom estilo centralista, interferir no que considerava conhecimento útil e nas determinaçōes sobre os curricula, os planos de estudo, os parâmetros de avaliação, entre outros.

Nas últimas décadas do século Xx, por contingências várias, ${ }^{6} \mathrm{O}$ Estado foi-se revelando inoperante nas funções de regulação e de provisão de bens e serviços que lhe estavam consignadas, mergulhando numa progressiva falta de credibilidade, vendo-se compelido a reposicionar-se e refazer as suas relaçōes com a sociedade. Para fazer face a essa situação, desencadeia uma série de reformas em que se desfaz de responsabilidades que até então lhe cabiam, transferindo-as para a sociedade e para o mercado. A uma lógica de regulação burocrática, consubstanciada no "exercício do poder pela autoridade, hierarquia e regulamentação formal" sucede uma lógica de "regulação de tipo mercantil", fundada no "exercício do poder pela influência", marcada pelos ajustamentos mútuos dos seus mecanismos e pelo "carácter difuso e informal das regras e das relaçôes” (Afonso, 2003, p. 51).

Algo idêntico ocorreu no terreno educativo, onde as necessidades sociais e educativas deixaram de encontrar resposta na uniformidade centralizada do sistema. À massificação do ensino, uma conquista democrática louvável, associaram-se a clara desadaptação da escola às novas realidades, as elevadas taxas de insucesso escolar e o abandono precoce, o que gerou um certo mal-estar dentro e fora da escola e avivou a necessidade da sua reestruturação urgente. 
Se isto aconteceu no ensino em geral, no ensino superior os resultados foram idênticos, o que coloca a universidade numa situação muito delicada. Acresce o facto de, como afirma Santos (1999), a um financiamento cada vez mais restritivo se contrapor uma exigência cada vez maior, fazendo eclodir uma série de problemas de ordem estrutural no seio de uma instituição que, fruto da rigidez organizativa e funcional que a caracterizou durante séculos, se revela claramente impreparada para a mudança. Além disso, para tentar repor o financiamento que o Estado deixa de lhe outorgar, a universidade vê-se na contingência de actuar no domínio da prestação de serviços, enquanto mão-de-obra especializada, dando azo à predominância de uma dimensão utilitarista em detrimento da sua dimensão cultural. Uma situação para a qual se torna imperioso encontrar alternativas, sob pena desta tendência contribuir para transformar a universidade numa espécie de "empresa orientada para o consumidor" (Readings, 2003, p. 21) e para a ir despojando de uma das suas principais missóes - a produção de cultura.

Trata-se de uma situação preocupante, dada a importância que os aspectos culturais assumem nos dias de hoje e a forma como interferem no nosso quotidiano. Como afirma Moreira (2005), estamos a viver uma revolução que, em boa parte, resulta da centralidade da cultura nas mudanças que se operam tanto na economia, na política, no mundo do trabalho e nas relaçōes sociais, quanto na formação das identidades pessoais e colectivas. Só que, a partir do momento em que se reconheceu que os processos culturais interferem de forma substancial na moral, nos padrōes de conduta adoptados na sociedade e na regulação das acções e das práticas, o esforço para os controlar tornouse mais intenso; no fundo, uma tentativa de regulação da cultura e/ou de regulação por meio da cultura (ibid.).

Assim se compreende que muitas das actuais reformas educativas e curriculares, anunciadas como imprescindíveis para melhorar a qualidade do ensino e para preparar a escola para lidar com a mudança e a diversidade de saberes e de culturas, ao serem operacionalizadas em torno das ideias de eficácia e eficiência no uso de recursos e procedimentos para alcançar determinados resultados preestabelecidos, acabem apenas por constituir uma forma subtil de regular o desenvolvimento do currículo e de reforçar o controlo dos alunos e dos professores. Uma situação que, na opinião de Contreras (1999), torna 
visível um dos maiores paradoxos das actuais políticas de reforma - o reforço do controlo da educação por parte do Estado e, simultaneamente, o seu abandono ao mercado - e contribui para fragilizar determinados pressupostos democráticos e culturais que deveriam nortear todo o processo.

$\mathrm{Na}$ verdade, a crescente desvalorização do discurso da democratização - que concebe a educação como um direito social e consigna à escola pública a responsabilidade da sua concretização - em prol da retórica da qualidade e da excelência - entendidas como germes de empreendedorismo e argumentos de modernização económica - tem concorrido para reforçar a ideologia meritocrática e transformar a universidade numa entidade competitiva, tanto no seio do próprio mundo académico como do mundo empresarial, isto é, no seio do mercado.

Associados a esta situação, existem mais dois aspectos que, pela importância que assumem na configuração do ensino superior contemporâneo e no quotidiano das universidades, não podemos deixar de referir.

O primeiro refere-se à emergência e consolidação de determinadas entidades supranacionais, como é o caso da Comunidade Europeia, cujas decisões conformam e restringem as decisões políticas das nações que estão sob a sua alçada, reduzindo assim a sua soberania. O desenvolvimento de tal processo, inserido numa dinâmica de globalização supranacional, baseia-se na construção de orientações e normas de acção comuns em diversos quadrantes e "responde deliberadamente a desafios sociais e económicos, perante os quais a educação, em geral, e o currículo, em particular, são chamados a desempenhar um papel central" (Pacheco \& Vieira, 2006, p. 87).

No que se refere ao sector educativo, os efeitos dessa dinâmica globalizadora expressam-se pela reconfiguração das formas de governação da educação e pela transformação dos processos de elaboração das políticas educativas, mudanças que têm ocorrido em perfeita sintonia tanto com a "constituição do mercado interno de serviços da Uniāo Europeia e o desenvolvimento do Acordo Geral de Comércio de Serviços", quanto com os "princípios e regras da Nova Gestão Pública", elementos estes de índole essencialmente neoliberal (Antunes, 2006, p. 86). Fazendo parte da estratégia de construção 
de um referencial europeu para a educação, Antunes (op. cit.) considera que todo o processo tem estado eivado de um significativo défice democrático, consubstanciado pelo afastamento dos princípios democráticos de representatividade, legitimidade e negociação que deveriam presidir a esse empreendimento, tem consentido a afirmação de mecanismos de regulação determinados por objectivos e tem contribuído para "reduzir a influência dos actores e interesses de expressão, âmbito e influência nacionais e subnacionais ao campo da execução das políticas". Uma situação preocupante que acabará não só por aniquilar grande parte do poder de decisão das instâncias nacionais em matéria educativa, mas também por concorrer para subjugar as universidades às nuances do mercado e para as transformar em locais privilegiados de aplicação de decisões externas.

No domínio curricular, a tendência tem sido para a progressiva europeização do currículo quer através da elaboração de propostas curriculares que obedeçam a referenciais bem definidos, quer pela implantação de critérios uniformes de organização curricular a diversos níveis de regulação política, quer ainda pela definição de resultados de aprendizagem (learning outcomes), de competências gerais e estratégicas comuns (Pacheco \& Vieira, 2006). Embora a tentativa de construir um território curricular europeu tenha radicado, até ao momento, mais em referenciais de estrutura organizacional do que na uniformização dos conteúdos programáticos, tudo indica que, a seu tempo, as opções curriculares acabarão por enfraquecer as territorialidades curriculares nacionais, regionais e locais a favor da legitimação de um conhecimento escolar internacional que represente não só as metas que, em termos de educação e formação, cada nação deve concretizar no quadro da Comunidade Europeia, mas também os interesses de certos sectores de influência e dos grupos sociais dominantes que se movem nesse contexto. ${ }^{7}$ No ensino superior, estas decisōes terão um impacto considerável, inviabilizando quer a possibilidade do currículo se transformar num instrumento flexível e integrador, quer a existência de currículos informais, necessários para "formar uma universidade a várias vozes e com múltiplas aberturas para coligações alternativas" (Santos, 1999, p. 199). Consequentemente, a universidade ver-se-á impossibilitada de se assumir, tal como seria desejável, como um espaço privilegiado de reflexão sobre o saber e sua importância na construção de uma sociedade mais justa e democrática e como uma via para a inclusão. 
O segundo aspecto, directamente relacionado com o anterior, diz respeito ao denominado Processo de Bolonha e às consequências que trouxe para as instituições de ensino superior da Comunidade Europeia. ${ }^{8}$ Constituindo um marco preponderante na reforma das instituições de ensino da Europa, o Processo de Bolonha traça como objectivos principais a edificação de um Espaço Europeu de Ensino Superior que viabilize a internacionalização das universidades, facilite a mobilidade de alunos e docentes, ${ }^{9}$ promova a empregabilidade dos cidadãos europeus e concorra para o desenvolvimento económico, social e humano da Europa -, a consolidação e enriquecimento da cidadania europeia e o aumento da competitividade com outros sistemas de ensino do mundo (em particular os dos Estados Unidos e do Japão).

Não deixando de reconhecer a bondade dos objectivos enunciados, concordamos com Amaral (2005, p. 41) ao denunciar a existência de "uma agenda oculta de Bolonha que é dominada pelas questôes da economia” e que, em detrimento da criação de uma área de ensino superior competitiva, procura, isso sim, resolver o problema dos elevados salários europeus que, no quadro da nova economia global, afectam os índices de competitividade da Europa:

A substituição crescente do termo "emprego" pelo termo "empregabilidade" e a introdução de um primeiro ciclo curto de formação, com relevância para o mercado de trabalho, podem ser vistos como discretas alterações políticas visando a criação de relações de trabalho mais flexíveis e a diminuição dos custos de mão-de-obra para promover a competitividade europeia e, ao mesmo tempo, diminuir os encargos públicos com o ensino superior, de forma mais eficaz do que um aumento de propinas.

Assumindo que se trata de uma visão economicista do Processo de Bolonha, Amaral (ibid., p. 43-44) justifica o seu pessimismo com base nas recomendaçôes que o Grupo de Trabalho E-Making the Best Use of Resources, criado pela Comissão Europeia para promover a implementação da Estratégia de Lisboa, apresentou em setembro de 2004, das quais se destacam: (i) não aumentar o financiamento público para o ensino superior; (ii) aumentar o financiamento privado quer através do aumento de propinas e de impostos aos detentores de um curso superior (graduate tax), quer do estabelecimento de parcerias público-privadas no ensino, quer ainda da concretização de contratos de 
investigação entre o ensino superior público e o sector privado; (iii) introduzir um sistema de empréstimos (income contingent loans) que viabilize a cada cidadão a sua formação ao longo da vida; (iv) regular os salários dos professores e a respectiva progressão na carreira em função da sua produtividade; (v) introduzir novos métodos de financiamento e gestão de projectos, assegurando assim uma eficaz rentabilização de recursos; (vi) criar sistemas de avaliação da qualidade e de acreditação da formação; (vi) estreitar a ligação entre propostas e benchmarks e (vii) proceder a uma avaliação sistemática das políticas de educação e de formação.

A concretização desta dinâmica economicista na educação pode acabar por subjugar as mudanças que vierem a desencadear-se nas universidades a critérios empresarias e de mercado, correndo-se o risco das prioridades atribuídas à eficiência e à competitividade se sobreporem aos preceitos democráticos que deveriam nortear os processos de produção e formação no ensino superior público.

Nesta ordem de ideias, importa levantar as seguintes questôes: Deverá a universidade transformar-se numa empresa? Estará o plano financeiro a asfixiar a missão da universidade e, em simultâneo, a permitir o afloramento de estratégias que visam a mercantilização do ensino? Poderá a universidade, nas condições actuais, assegurar uma educação que contribua para a afirmação pessoal de cada indivíduo, para o desenvolvimento da cidadania e para o fortalecimento da democracia? Como podem as universidades garantir a sua liberdade académica e de crítica social?

\section{Alguns desafios pedagógicos e curriculares}

Procurámos ao longo deste texto desocultar alguns dos sentidos que estão na base das transformações que se têm desencadeado no ensino superior, anunciadas como imprescindíveis para a universidade poder dar resposta aos intensos e complexos desafios com que se depara actualmente. Um conjunto de desafios que, como temos sucessivamente vindo a referir (Morgado, 2006, 2007), se circunscrevem a quatro dimensões fundamentais: (i) as profundas mudanças que as transformações políticas, científicas, económicas e sociais imprimiram no paradigma civilizacional contemporâneo; (ii) as exigências decorrentes 
da emergência da sociedade da informação e do conhecimento; (iii) a preparação dos novos públicos escolares que passaram a frequentar as universidades; (iv) o reajustamento da oferta formativa, como meio de resposta a ambientes sociais cada vez mais complexos e em permanente reconfiguração.

Parece-nos oportuno, por isso, reflectir sobre algumas das mudanças que devem operar-se no interior da universidade e sem as quais será difícil conseguir a tão propalada modernização académica, essencial para que cada indivíduo faça frutificar as suas potencialidades numa sociedade em permanente mutação, aprenda a usufruir os benefícios das modernas tecnologias de acesso à informação e ao conhecimento e desenvolva capacidades de aprendizagem ao longo da vida.

Convém referir que a magnitude de tal empreendimento impede que este se circunscreva apenas ao interior das instituiçóes educativas. A melhoria do fenómeno educativo depende do esforço colectivo dos distintos parceiros sociais, cabendo à universidade a responsabilidade de encetar as alteraçóes necessárias para alcançar o protagonismo que durante séculos lhe coube. É nossa convicção de que, para superar os constrangimentos que fomos aflorando ao longo desta análise, a universidade deverá cumprir internamente algumas condiçôes, das quais se salientam: (1) o recurso a procedimentos de mediação educativa; (2) a transformação do modelo pedagógico da universidade; (3) a mudança das práticas docentes.

\section{O recurso a procedimentos de mediação educativa}

A transformação do paradigma civilizacional a que aludimos acima, bem como as exigências que com ela emergiram, tornaram visível a necessidade da sociedade se (re)equacionar como sociedade de aprendizagem (Fullan, 2002) e de encontrar equilíbrios e modelos de desenvolvimento capazes de solver os múltiplos problemas associados aos novos modos de vida, às desigualdades, às tensōes e aos conflitos que todo esse processo transformacional provocou.

Situando-se na zona de confluência dos múltiplos sistemas que integram e interagem na sociedade, a escola, em particular a universidade, acaba por "espelhar" as relações, tensōes e contrariedades aí existentes. $\mathrm{Na}$ escola convivem tendências antagónicas como, por exemplo, 
"a necessidade de mudança e a resistência à mudança", e rivalizam diferentes modelos, perfilhados pelos seus protagonistas, vendo-se, por isso, compelida a delinear "estruturas de interacção e figuras facilitadoras dessa interacção" (Amado, Freire \& Caetano, 2005, p. 5). Além disso, ao estar incumbida da educação para a cidadania e de contribuir para o progresso e para o desenvolvimento democrático da sociedade, a escola vê-se, ainda, na contingência de criar condições que permitam aos jovens desenvolver competências tanto de índole científica e profissional, como de teor comunicacional, afectivo e moral. Neste contexto, a mediação é vista como uma área propícia para a concretização de tais propósitos, sobretudo se for estruturada na base da reflexividade crítica e do questionamento ético.

Entendida como um modo de prevenir, gerir e/ou resolver situações conflituosas - quer as resultantes da própria heterogeneidade cultural, social e ética dos alunos que frequentam a escola, quer da falta de equilíbrio entre competitividade e cooperação, quer ainda da falta de reconhecimento dos trabalhos realizados (Vinyamata, 2003) -, com base em competências de investigação, de comunicação e de intervenção, a mediação educativa contribui para o desenvolvimento cabal da personalidade humana e para facilitar as interacções pessoais. Quer através de "estruturas formais que desenvolvam processos de negociação e de resolução de conflitos na escola", quer pela preparação dos diversos protagonistas "para aplicar, no seu quotidiano, os conceitos e competências de aprendizagem no domínio cognitivo e social", a mediação surge como um elemento nuclear no desenvolvimento de um pensamento crítico e na assunção de responsabilidades individuais e colectivas, em prol de uma sociedade mais justa e igualitária (Amado, Freire \& Caetano, 2005, p. 3).

Em idêntica linha de pensamento, Schnitman (1998) assevera que a mediação opera entre o existente e o possível e envolve um conjunto de práticas que tendem à resolução alternativa de conflitos. Socorrendo-se de procedimentos que favorecem o respeito pelas diferenças, o desenvolvimento de capacidades para lidar com a diversidade e a contradição, a concretização de acordos e a gestão da complexidade do mundo actual, a mediação procura gerar formas de acção e relação não-litigantes, que contribuam para a construção de práticas democráticas. 
Porém, o recurso a procedimentos de mediação educativa e curricular, como meio de resolução de problemas/conflitos e de transformação da escola, requer a existência de profissionais preparados, com particular destaque os professores, a quem incumbe a tarefa de conceber, operacionalizar e avaliar os processos de ensino e aprendizagem que aí se realizam. Não deixando de reconhecer a persistência de "uma visão conservadora da relação pedagógica e das relações de poder que nela se estabelecem", bem como de uma certa tendência para perpetuar "uma visão muito compartimentada da intervenção educativa" (Amado, Freire \& Caetano, 2005, p. 2), estou convicto de que é possível uma transformação profunda do paradigma educacional contemporâneo na base de uma mudança de mentalidades, de uma maior maturidade curricular e de uma transformação do modelo pedagógico e das práticas docentes que imperam nas nossas instituições educativas, especificamente no ensino superior.

A transformação do modelo pedagógico na universidade

Como acabámos de constatar, só faz sentido falar de mediação educativa se esta estimular o desenvolvimento de atitudes cooperativas e competências comunicacionais pelos distintos actores que configuram o fenómeno educativo, concorrendo assim para o exercício de uma cidadania responsável. No fundo, uma forma de potenciar um modelo educativo que não se restrinja à mera transmissão de conhecimentos e dê voz aos distintos protagonistas dos processos de ensino-aprendizagem; um modelo que estimule a participação, a discussão e a negociação e que, numa perspectiva dialéctica, faça do conflito e da crítica verdadeiras oportunidades de aprendizagem.

Parece não suscitar grande controvérsia a ideia de que na universidade, durante muito tempo detentora do monopólio da produção e divulgação de saberes, foi vigorando um modelo de ensino em que as questôes científicas e a excelência da retórica se sobrepunham às questôes de índole pedagógico-didáctica, tidas como de menor relevância. Um modelo que se foi perpetuando no tempo e contribuiu para que a reflexão pedagógica nunca fosse, como assegura Garcia (2001, p. 35), uma "prática corrente no meio universitário português", nem o ensino crítico conseguisse impor-se, permitindo que as práticas de tipo escolástico realizassem tranquilamente o seu caminho. Um modelo que foi fazendo da 
transmissão de conhecimentos e da reprodução de saberes dois dos seus pilares fundamentais: "O ensino, nestes casos, é somente um reprodutor de saber. Não inova. Não critica. Só consome as ideias de outros e por isso estará mais condenado porque a lógica da sociedade lhe será hostil" (Garcia, op. cit., p. 36).

A esta situação não foi alheio o facto de, na universidade, ter prevalecido uma organização curricular estruturada na base de disciplinas, assumidas como territórios instituídos de poder, o que foi facilitando a fragmentação do conhecimento e estimulando a especialização de funções. Além de se nutrir de uma concepção técnica de currículo, isto é, como conjunto de objectivos e de conteúdos predefinidos que a escola deve concretizar, a organização do conhecimento por disciplinas propiciou uma visão espartilhada e/ou estigmatizada da realidade e favoreceu a emergência de uma cultura curricular baseada no individualismo dos professores.

Com a afirmação da sociedade do conhecimento e das transformações que lhe estiveram associadas, este modelo de ensino foi-se revelando deficitário para munir os estudantes de competências indispensáveis à sua futura realização pessoal, social e profissional, e, consequentemente, de os apetrechar com as capacidades necessárias para prosseguirem a aprendizagem ao longo da vida, em contextos de mudança e inovação contínuas. Como lembra Fermoso (1989, citado por Garcia, 2001, p. 35), "educar numa cultura de mudança é educar para a constante readaptação", evitando assim os possíveis desfasamentos entre a "vida real" e a vida escolar; um ensejo só possível com base na compreensão de que a cultura permeável à mudança não é compaginável com um estilo de educação universal e permanente. Daí a necessidade da universidade transformar o modelo pedagógico que tem imperado no seu seio.

Em vez de um modelo de educação que privilegia o ensino de saberes, que faz da memorização o seu pilar fundamental e que vai prolongando o seu divórcio com a vida, torna-se necessário desenvolver dinâmicas que recorram ao debate e à reflexão e criar condições para que os estudantes se assumam como os principais protagonistas das suas próprias aprendizagens e possam conferir sentido e utilidade ao que aprendem na escola. No plano do ensino-aprendizagem, é imperioso que o núcleo enfático se desloque do ensino para a aprendizagem e que a produção do conhecimento vise, sobretudo, as suas aplicações a situações reais do quotidiano, deixando de prevalecer a construção/transmissão 
do conhecimento pelo conhecimento (Quintanilha, 2003). No fundo, um modelo de educação que persiga o que Carrilho (1995) identifica como construção de um know-how intelectual.

Impōe-se neste momento reflectir sobre os desafios que todas estas transformaçôes carrearam em termos de profissionalidade e profissionalismo docente.

\section{A adopção de outro perfil de docente universitário}

A actividade profissional docente (em especial no ensino superior), fundamental na mudança ou melhoria das instituições educativas, está muito para além dos conteúdos funcionais que lhes estão prescritos, corporizando o que Organ (1988, p. 4), designa como "comportamentos de cidadania organizacional", para se referir ao conjunto de "comportamentos discricionários, indirecta ou explicitamente reconhecidos pelo sistema de recompensa formal e que, em conjunto, promovem o funcionamento eficaz da organização".

Assim sendo, o perfil do professor universitário vê agregarem-se às competências científicas outras de índole pedagógica, relacional e de gestão, que ganham grande visibilidade e demonstram a natureza compósita das competências profissionais que hoje se exigem nesse nível de ensino. A dimensão pedagógica torna-se uma faceta da qualidade do ensino superior, fazendo deslocar a concepção do ensino centrada professor e nos conteúdos para uma concepção de ensino centrada na aprendizagem e no aprendente (Zabalza, 2003). Isto é, ao modelo do saber a transmitir sobrepóe-se um modelo do saber a (re)construir.

As próprias características dos novos conhecimentos e seu fácil acesso (rapidez, volume, variedade...) deslocam a acção do professor da transmissão de conhecimentos para o desenvolvimento de capacidades (selecção, utilização, análise, crítica...). Já não é aceitável a existência de professores que funcionam predominantemente como antenas parabólicas, sempre disponíveis para "(re)transmitir tudo aquilo que lhe propõem ou lhe impōem" (Gomes, 2006, p. 43-44). Aqui poderá, segundo Warnock (2003), situar-se o novo papel das universidades, em que o professor dogmático dá lugar ao professor dialogante.

A ser assim, as instituições de ensino vão-se tornando comunidades de aprendizagem dialógica (Imbérnon, 1999), onde as "habilidades 
comunicativas" tornam mais participado e reflexivo todo o processo, vendo-se a racionalidade instrumental na contingência de ser superada pela acção comunicativa.

Tais mudanças implicam, naturalmente, novas visões sobre o conhecimento, e respectivas abordagens teóricas e práticas, o que exige professores preparados em valências como a autonomia crítica e emancipatória. Uma forte preparação científica, capacidades relacionais, espírito de grupo, tomada de decisões etc. são dimensões que definem o perfil deste "novo" professor. Já não é, apenas, a formação teórica, mas também a prática e pela prática, num processo contínuo de desenvolvimento ao longo da sua carreira (Day, 2001).

Se a investigação e a produção de conhecimento continuam a constituir um lugar-chave na acção dos professores do ensino superior, a pedagogia agrega-lhes uma dimensão decisiva, assim equiparando o mérito da pesquisa ao mérito do ensino, assim valorizando uma dimensão mais fluida, e na aparência mais frágil, mas de efeito mais perdurável (Antunes, 2001). Investigar e ensinar constituem duas competências decisivas na criação de condições para que os alunos se desenvolvam, cresçam, sejam e se realizem como pessoas, cidadãos e profissionais (Dias, 2001).

Cumpridos estes pressupostos, a universidade reunirá condições para propiciar um verdadeiro "encontro de saberes", germinando em comunidades interpretativas e conciliando a função de conhecimento crítico que deve caracterizar a universidade com a criação de espaços de interacção pessoal e social (Santos, 1999). A alteração substantiva dos contextos educacionais, uma nova postura da universidade e seus agentes, aliada a uma transformação da matriz curricular são as chaves que permitem a superação de um curriculum de índole academicista, derramado em celas disciplinares, sem articulação horizontal, resistente às contextualizaçōes, por um curriculum flexível, integrador quer no plano dos conhecimentos, quer no plano dos agentes, com as suas múltiplas variáveis. Estaremos, em síntese, perante curricula que, num mundo global, se constituirão meio de resolução de problemas locais.

Caso contrário, a universidade contribuirá para fazer prevalecer o primado da certificação sobre o primado da construção de saberes e do desenvolvimento de competências, adiando uma oportunidade 


\section{única para se assumir como espaço de oportunidades e como esteio da democracia, e acabando, inevitavelmente, por se transformar num ter- reno de desigualdade(s).}

\section{Recebido em maio de 2008 e aprovado em junho de 2008.}

\section{Notas}

1. Na opinião do autor, tais exigências contribuíram para as progressivas desestruturação e perda de protagonismo do Estado a favor do mercado e para a redução do peso das políticas sociais ao nível das políticas públicas.

2. Tal como acontece noutras áreas, também neste sector se verificam situaçōes de extrema desigualdade, com cerca de 20 países industrializados a constituírem "uma fatia esmagadora do mercado mundial de serviços e equipamentos de telecomunicações", o que lhes confere poder suficiente para "impor e garantir mudanças profundas" no domínio das telecomunicações (Santos, 2002, p. 47).

3. Para uma análise do processo de europeização das políticas educativas e dos novos papéis consignados ao Estado, ver Antunes (2001).

4. Para urdir esta afirmação, Teodoro (2001, p. 157) socorreu-se do conceito de lugar estrutural proposto por Santos (1995, p. 420-421). Segundo o autor, os lugares estruturais são espaços onde se produzem práticas sociais específicas que se podem caracterizar como um "conjunto de relações sociais cujas contradiçôes internas asseguram uma dinâmica endógena específica”. Identifica seis lugares estruturais - doméstico, trabalho, mercado, comunidade, cidadania e mundial.

5. Concordamos com Bonal (2006) ao afirmar que um dos motivos que está na base da denominada "crise educativa" é a acumulação de responsabilidades e tarefas que se têm exigido à escola, procurando que actue como "mecanismo amortecedor do mal estar social e como bode expiatório a quem há que exigir responsabilidades". Será esta uma exigência legítima? Não será apenas uma forma de descartar responsabilidades de outros sectores sociais?

6. A recessão económica da década de 1970 , a superação da eficácia socializadora e da homogeneização cultural da Nação por uma ideologia de mercado (Tedesco, 2000), a progressiva massificação do ensino, a incapacidade da gestão centralista delinear medidas de combate à rápida obsolescência do conhecimento (Amaral \& Magalhães, 2000), o aumento das taxas de desemprego no seio dos diplomados, a sensação de inoperância do Estado, para assegurar a produção e distribuição de bens e serviços, a que se sobrepõe a ideia de um mercado eficaz e de um Estado mínimo (Benítez, 2000), são algumas das razōes que despoletaram a perda de protagonismo do Estado como figura central da vida económica, social e cultural.

7. Na opinião de Pacheco e Vieira (2006, p. 94-95), a definição de medidas de homogeneização dos conteúdos programáticos terá lugar após a "harmonização dos parâmetros que definem a organização curricular" e será feita, prioritariamente, "em áreas-chave do conhecimento e nas designadas áreas de Formação Pessoal e Social, a que não são alheios, por questôes políticas, os temas da cidadania europeia e do multiculturalismo". 
8. Cf. Recomendação do Conselho Europeu sobre a cooperação europeia para a garantia da qualidade do ensino superior, publicada no Diário Oficial da Comunidade Europeia, em 7 de outubro de 1998.

9. Para tornar possível a mobilidade é necessário que se cumpram duas condições: a existência de um idêntico formato organizacional dos ciclos de formação e a adopção de um sistema de créditos (ECTS) que facilite o reconhecimento mútuo de classificações. A propósito da criação do sistema de ECTS, Amaral (2005, p. 42) chama a atenção para a dificuldade de "definir de forma precisa o que é um ECTs", sobretudo pelo facto da sua medição ser feita com base no "trabalho de um aluno médio", o que nunca permitirá que o ЕСTs se afirme como "uma moeda fiável para o reconhecimento de estudos", nem garantirá a necessária credibilidade a um sistema de créditos acumuláveis. Daí o recurso com mais insistência à definição de learning outcomes por cada disciplina.

\section{Referências}

AMADO, J.; FREIRE, I.; CAETANO, A. Programa do Curso de Mestrado em Ciências da Educação. Lisboa: FPCE; Universidade de Lisboa, 2005. (policopiado).

AMARAL, A. Bolonha, o ensino superior e a competitividade económica. In: Serralheiro, J.P. (Org.). O Processo de Bolonha e a formação dos educadores e professores portugueses. Porto: Profediçōes, 2005. p. 35-45.

AMARAL, A.; MAGALHÃES, A. O conceito de stakeholder e o novo paradigma do ensino superior. Revista Portuguesa de Educação, Braga, v. 13 , n. 2, p. 7-28, 2000.

ANTUNES, F. Os locais das escolas profissionais: novos papéis para o Estado e a europeização das políticas educativas. In: STOER, S.; Cortezão L.; Correia, J. A. (Org.). Transnacionalização da educação: da crise da educação à "educação" da crise. Porto: Afrontamento, 2001. p. 163-208.

ANTUNES, F. Governação e espaço europeu de educação: regulação da educação e visóes para o projecto 'Europa'. Revista Crítica de Ciências Sociais, Coimbra, n. 75, p. 63-93, 2006.

ANTUNES, J. L. Numa cidade feliz: ensaios. Camarate: Círculo de Leitores, 2001.

AZEVEDO, J. O fim de um ciclo: a educação em Portugal no início do Século XXI. Porto: Asa, 2002. 
BENÍTEZ, M.P. Estado y educación: una relación histórica. In: RuIZ, A. (Coord.). La escuela pública: el papel del Estado en la educación. Madrid: Biblioteca Nueva, 2002. p. 17-48.

BONAL, X. "Reconfigurações": escola e Estado e novas definições de mudança social. In: Magalhães, A.; Stoer, S. (Org.). Reconfigurações: escola, Estado e cultura numa época de globalização. Porto: Profedições, 2006. p. 89-114.

CARRILHO, M.M. Aventuras da interpretação. Lisboa: Presença, 1995.

CONTRERAS, J. Autonomía por decreto?: paradojas en la redefinición del trabajo del profesorado. Educational Policy Analysis Archives, Arizona, v. 7, n. 17,1999 .

DAY, C. Desenvolvimento profissional de professores: os desafios da aprendizagem permanente. Porto: Porto, 2001.

FULLAN, M. Las fuerzas del cambio: explorando las profundidades de la reforma educativa. Madrid: Akal, 2002.

GARCIA, R. Para um ensino superior com qualidade. Revista Portuguesa de Ciências do Desporto, Porto, v. 1, n. 1, p. 33-43, 2001.

GOUVEIA, T. A globalização como fenómeno de homogeneização cultural. In: BRITO, J.M. (Coord.). Globalização e democracia: os desafios do século XXI. Lisboa: Colibri, 2003. p. 13-21.

IMBÉRNON, F. Desafios e saídas educativas na entrada do século. In: Imbérnon, F. (Org.). A educação no século XXI. Porto Alegre: Artes Médicas, 1999. p. 21-36.

JESSOP, B. Globalização e o império da informação. Viseu: Pretexto, 2005.

LOPES, A. Encruzilhadas do desenvolvimento: falácias, dilemas, heresias. Revista Crítica de Ciências Sociais, Coimbra, n. 75, p. 41-61, 2006.

MOREIRA, A.F. O processo curricular do ensino superior no contexto atual. In: Veiga I.; Neves, M. (Org.). Currículo e avaliação na educação superior. Araraquara: Junqueira \& Marin, 2005. (policopiado).

MORGADO, J.C. Globalização e (re)organização do ensino superior: perplexidades e desafios. Perspectiva, Florianópolis, v. 24, n. 1, p. $205-$ 228, 2006. 
MORGADO, J.C. Globalização, ensino superior e currículo. In: Moreira, A.F.B.; Pacheco, J.A.; Morgado, J. C. (Org.). Globalização e (des)igualdades: desafios contemporâneos. Porto: Porto, 2007. p. 61-72.

ORGAN, D. Organizational citizenship behavior: the good soldier syndrome. Lexington, MA: Lexington Books, 1988.

PACHECO, J.A.; VIEIRA, A.P. Europeização do currículo: para uma análise das políticas educativas e curriculares. In: MoreirA, A.F.B.; Pacheco, J.A (Org.). Globalização e educação: desafios para políticas e práticas. Porto: Porto, 2006. p. 87-126.

PETRELLA, R. O bem comum: elogio da solidariedade. Porto: Campo das Letras, 2002.

PNUD. Relatório do Desenvolvimento Humano 2005. Resumo. Disponível em: <http://hdr.undp.org/reports/global/2005/portuguese/ pdf> Consulta em: 25 set. 2007.

QUINTANILHA, A. Para lá dos que nos ensinaram. In: QUINTANILHA, A. et al. Cruzamento de saberes: aprendizagens sustentáveis. Lisboa: Fundação Calouste Gulbenkian, 2003. p. 23-33.

READINGS, B. A universidade em ruinas. Coimbra: Angelus Novus, 2003.

SANTOS, B.S. Toward a new common sense: law, science and politics in the paradigmatic transition. New York: Routledge, 1995.

SANTOS, B.S. Reinventar a democracia. Lisboa: Gradiva; Fundação Mário Soares, 1998.

SANTOS, B.S. Pela mão de Alice: o social e o político na pósmodernidade. Porto: Afrontamento, 1999.

SANTOS, B.S. (Org.). Globalização: fatalidade ou utopia? 2. ed. Porto: Afrontamento, 2002.

SCHNITMAN, D.F. Nuevos paradigmas, cultura y subjetividad. Buenos Aires: Paidós, 1998.

SIMÃO, J.V.; SANTOS, S.M.; COSTA, A.A. Ensino superior: uma visão para a próxima década. Lisboa: Gradiva, 2003. 
STOER, S. Desocultendo o voo das andorinhas: educação inter/ multicultural crítica como movimento social. In: STOER, S.; CorTEZĀo L.; Correia, J. A. (Org.). Transnacionalização da educação: da crise da educação à "educação" da crise. Porto: Afrontamento, 2001. p. 245-275.

TEDESCO, J.C. O novo pacto educativo. Vila Nova de Gaia: Fundação Manuel Leão, 2000.

TEODORO, A. Organizações internacionais e políticas educativas nacionais: a emergência de novas formas de regulação transnacional, ou uma globalização de baixa intensidade. In: Stoer, S.; Cortezão L.; Correia, J. A. (Org.). Transnacionalização da educação: da crise da educação à "educação" da crise. Porto: Afrontamento, 2001. p. 125-161.

VINYAMATA, E. Comprender el conflicto y actuar educativamente. In: Vinyamata, E. (Coord.). Aprender del conflicto. Barcelona: Graó, 2003. p. 9-28.

WARNOCK, M. Desafios universitários numa sociedade do conhecimento. In: Friedlander, A.H. et al. Globalização, ciência, cultura e religioes. Lisboa: Dom Quixote, 2003. p. 249-255.

WOLTON, D. A outra globalização. Algés: DIfel, 2004.

ZABALZA, M. Competencias docentes del profesorado universitário: calidad y desarrollo professional. Madrid: Narcea, 2003. 